\title{
Australian parents' perceptions of factors that influence their children's pork consumption: an exploratory qualitative study
}

\author{
Elizabeth P. Neale ${ }^{1,2}$, Deborah J. Nolan-Clark ${ }^{1}$ and Karen E. Charlton ${ }^{2 *}$
}

\begin{abstract}
Background: Pork provides key nutrients such as protein, thiamin and selenium, however fresh pork is not commonly included in the diets of Australian children, with processed pork preferred. Current dietary guidelines emphasise the consumption of fresh meat in preference to processed meat, and childhood eating habits are likely to persist throughout the lifespan. Investigation of factors influencing children's pork consumption is therefore warranted. The aim of this exploratory study was to investigate parents' perceptions of factors that affect their children's consumption of pork and to identify barriers to the intake of fresh pork, in particular.
\end{abstract}

Methods: Six semi-structured focus group interviews were conducted with $n=31$ parents or carers of children aged 2 to 16 years. Interviews were digitally recorded, transcribed verbatim and analysed thematically according to the framework analysis technique and using NVivo qualitative analysis software. Key themes and sub-themes were identified, and exemplar quotes for each theme were identified.

Results: A number of key themes emerged during the focus groups, namely: a lack of confidence and knowledge relating to the preparation and cooking of fresh pork, poor acceptability of fresh pork by some children due to taste and texture and the influence of family and cultural traditions on pork consumption. Parents reported an overall perception that fresh pork was a healthy meat, but a low visibility of pork in shopping outlets and limited advertising restricted its uptake. Participants discussed a need for pork recipes and cooking instruction to build confidence in their ability to prepare fresh pork dishes.

Conclusions: This exploratory qualitative study is the first to explore factors influencing children's pork consumption and has provided key insights into children's eating behaviour in relation to pork. These factors may inform targeted dietetic strategies, including recipe development and the provision of information on nutrient composition and cooking strategies, to encourage dietary diversity regarding meat choices for families with young children.

Keywords: Pork, Processed meat, Meat, Children, Barriers, Preferences, Focus groups

\section{Background}

The Australian Dietary Guidelines recommend the regular consumption of lean meat or alternatives for all Australians, including children [1]. Conversely, guidelines recommend limiting the intake of processed meat, due to its association with diseases including colorectal cancer [2]. Pork provides a unique

\footnotetext{
*Correspondence: karenc@uow.edu.au

${ }^{2}$ School of Medicine, Faculty of Science, Medicine and Health, University of Wollongong, New South Wales, Australia

Full list of author information is available at the end of the article
}

case study, as whilst fresh pork is a lean meat that provides several key nutrients which are required for growth and development, including protein, thiamin and selenium [3, 4]. Processed pork (including bacon and ham) is more frequently consumed. Secondary analysis of the nationally representative 2007 Australian National Children's Nutrition and Physical Activity Survey [5] found that whilst approximately half of the surveyed children reported consuming some kind of pork on the days of the survey, only $14 \%$ of these children ate fresh pork (such as pork chops, leg, steaks, ribs, fillets and 
mince), with an overwhelming proportion consuming processed pork products such as bacon and ham [6]. In comparison, fresh cuts of beef, lamb and chicken were consumed more frequently than their processed counterparts [7], suggesting differences in eating habits between these meat types and pork. These findings have been also been supported by more recent data, with preliminary results from the 2011-2012 Australian Health Survey also suggest that ham is the most widely consumed processed meat by Australians overall and is eaten by a substantially greater proportion of individuals than unprocessed pork (12.2\% as compared to $4.9 \%$ [ [8].

The tendency to consume processed rather than fresh varieties of pork amongst children may also be pertinent given that dietary habits formed during childhood may persist throughout adult years [9-11]. Understanding barriers and motivating factors that influence the intake of both fresh and processed pork amongst children may provide key insights to inform targeted dietary change in replacing processed options with fresh varieties.

Parents and caregivers have a significant influence on the dietary intake and eventual food preferences of their children [12] and can contribute important insights into their children's eating behaviours. Focus groups allow for exploration of participant's attitudes and perceptions by facilitating group discussion not provided by other qualitative methods such as surveys or one-on-one interviews $[13,14]$. Such exploration is essential when seeking to gain insights into dietary choices. Previous studies examining consumer perceptions of pork consumption have primarily focused on European adults [15-19]. There is a paucity of qualitative literature exploring children's pork preferences and eating habits in the Australian context.

The aim of this exploratory study was to investigate parents' perceptions of factors affecting their children's consumption of pork and to identify barriers to the intake of fresh pork, in particular.

The results of this study may be useful to inform targeted strategies to encourage the preferential intake of fresh pork, over processed varieties, ensuring that children's meat consumption may be more consistent with current dietary guidance.

\section{Methods}

Semi-structured focus group interviews were conducted amongst parents and carers of children to assess pork consumption patterns and perceived barriers to fresh and total pork intake.

Participants were initially recruited from a shopping centre in Wollongong, New South Wales, Australia, a regional centre $80 \mathrm{~km}$ south of Sydney. To ensure that working parents were also included in the research, email invitations were sent to all general and academic staff at the University of Wollongong. Participants met the study inclusion criteria if they were a parent or carer of a child aged 2-16 years who consumed meat and who was involved in food purchasing and/or preparation. The age range was chosen to align with that of the nationally representative Australian National Children's Nutrition and Physical Activity Survey [5]. Participants were excluded if they could not speak conversational English. All interested participants were provided with an information sheet which outlined the research and were provided with a parking voucher to attend focus groups at the University of Wollongong. Ethical approval for the study was granted by the University of Wollongong/ Illawarra and Shoalhaven Local Health Network District Social Science Human Research Ethics Committee (HE 13/429) and signed informed consent was obtained from all participants.

All focus groups were conducted in December 2013 and each ran for approximately $1 \mathrm{~h}$. As recommended by Wong [20] and Krueger and Casey [21], each group was run by an experienced moderator (DNC), who was responsible for guiding the discussion, with an observer (EN or KC) present to take notes on both the discussion and non-verbal cues made by participants, such as facial expression and body language. At the beginning of each session, participants were oriented to the purpose of the focus groups and were informed that all data would be de-identified prior to analysis. Participants were encouraged to express their thoughts freely. All participants completed a brief questionnaire providing basic demographic details and information regarding their role in food preparation/purchasing and the number and age of their children prior to the focus group.

Discussion questions were developed based on consensus between study investigators, following the procedures outlined by Krueger and Casey [21]. Discussion questions were standardised (see Fig. 1) to ensure comparability of results between groups. Questions were related to participants' opinions about their children's eating habits with a specific focus on pork and addressed factors which encouraged or discouraged pork consumption, as well as consumption of specific types of pork. Where appropriate, probing questions were used to allow participants to clarify or expand on comments.

\section{Data analysis}

Demographic data was analysed using Statistical Package for Social Sciences (SPSS) Version 17.0 (SPSS Inc., Chicago, IL, USA). Where necessary, chi-squared analyses were conducted to compare results between participants recruited from the shopping centre and 


\begin{abstract}
1. When you think of meat in general, what types of thoughts come to mind?
2. What types of meat do your children eat?

2a. Follow-up questions to explore further: Why do they eat/not eat that type of meat? Child's preferences (pork in particular), family preferences, cost, convenience, health, familiarity?

3. When you think of pork specifically, what types of thoughts come to mind?

3a. Probe regarding categories/types of pork and thoughts/opinions on these

4. What have been your experiences with your children eating fresh pork/you preparing and serving it as a family meal?

4a. Probe regarding parent's cooking experiences with pork, how it was cooked, types cooked, any issues with taste/flavour/texture following meal preparation

5. What types of pork do your children eat?

5a. Probe: do they eat fresh or processed pork and why/why not? What are their favourite types to eat?

6. Why do they eat/not eat pork or specific types of pork?

6a. Probe: Child's preferences, family preferences, cost, convenience, health, familiarity?

7. What do you think would encourage your children to eat more fresh pork?

8. What do you think are the barriers to your children eating more fresh pork?

8a. Probe: child's or family's preferences, cost, familiarity?

9. What are the factors that influence the types of pork you choose to buy/prepare for your children?

9a. Probe: price, perceived healthfulness, country of origin, recipe familiarity
\end{abstract}

Fig. 1 Discussion questions asked during the focus groups

via the University of Wollongong. All focus groups were digitally recorded, transcribed verbatim and deidentified. Focus group transcripts were uploaded into a computer software package, NVivo 10 for Windows (QSR International Pty Ltd, Melbourne, Australia, 2014) for data analysis.

Focus group data were analysed according to the framework analysis technique [22, 23]. This method has been used widely in health-based qualitative research [24-26], including studies focusing on childhood [27-30].
As prescribed by the analysis method, investigators initially familiarised themselves with the data by studying transcripts and observation notes, noting non-verbal cues where relevant. A thematic framework was then identified, and the transcribed data was coded into a number of relevant sub-themes. These sub-themes were then grouped and mapped into a number of larger themes, representing a broader conceptual framework. Final thematic analysis, categorisation and conclusions were reached by consensus of all members of the research team. Exemplar key 
quotations were identified within each theme in order to illustrate the views of the participants, with a range of views identified in the case that divergent responses occurred.

\section{Results and discussion}

Fifty-one individuals expressed interest in participating in the focus groups. Six focus groups with 31 participants in total were completed. The reasons for interested individuals not participating in the groups included other time commitments and an inability to speak conversational English. Most participants were female and were the main food purchaser and the person responsible for food preparation in their household (Table 1). When considering only children in the target age range of $2-16$ years, the median age of participants' children was 7 years (range: 2-16 years); however due to some participants also having children who were younger or older than the target range, the median age of all participants' children was also seven, although ages ranged from 1 to 26 years old. Over $70 \%$ of participants had a university education, but level of education did not differ between participants

Table 1 Characteristics of focus group participants

\begin{tabular}{ll}
\hline Gender: & \\
- Females & $24(77.4 \%)$ \\
- Males & $7(22.6 \%)$ \\
Mean age of participants & $42.5 \pm 7.4$ years \\
Highest level of education: & \\
- Year 10 & $0(0 \%)$ \\
- Year 12 & $2(6.5 \%)$ \\
- TAFE or equivalent & $5(16.1 \%)$ \\
- University & $23(74.2 \%)$ \\
- Not stated & $1(3.2 \%)$ \\
Number of children: & \\
- One child & $8(25.8 \%)$ \\
- Two children & $15(48.4 \%)$ \\
- Three children & $6(19.4 \%)$ \\
- Four children & $2(6.5 \%)$ \\
Main food purchaser: & \\
- Yes & $17(54.8 \%)$ \\
- No & $2(6.5 \%)$ \\
- Shared with partner & $12(38.7 \%)$ \\
Main food preparer: & \\
- Yes & $10(32.3 \%)$ \\
- No & \\
Mean age of children (in selected age range only) & \\
Mean age of all children & \\
\hline & \\
\hline
\end{tabular}

recruited at the local shopping centre $(n=9)$ and those recruited from the University of Wollongong $(n=22)$ $\left(x^{2}(3)=4.94, p=0.18\right)$.

A summary of the key themes and sub-themes which emerged during the focus groups are shown in Table 2 and discussed in detail below. Data saturation was observed by the fourth group, indicating that a comprehensive understanding of the topic was achieved.

\section{Family pork practices}

Participants frequently referred to their children's pork consumption as being driven by their own dietary preferences. As many of the participants were the primary person responsible for food preparation in the household, they often chose to serve dishes to their families which they themselves enjoyed. This practice has previously been reported in the literature and may encourage the child's liking for these foods over time [31]. Improving parental acceptance and willingness to prepare dishes that contain fresh pork may be a way in which to improve fresh pork consumption in children.

"To be honest I probably don't always shop with the children in mind...often we'l have pork if we have people over.... so we'll cook with it, but for the kids we just tell them they're eating it"

(Group 1, male, mean child age 6.5 years)

\section{Pork as part of tradition and culture}

Family and cultural traditions were highlighted as having a large impact on the frequency and type of pork participants served to their families. The cultural background of participants and their partners strongly influenced their decisions to provide pork to their children, with participants of Asian heritage in particular citing cultural traditions as influencing their consumption of fresh pork. This finding is consistent with the patterns of pork consumption seen in a previous analysis of the 2007 Australian National Children's Nutrition and Physical Activity Survey, where a higher proportion of children from an Asian background reported consuming fresh pork than those with a primary caregiver from Australia or Europe [6].

"I guess it's more cultural, pork is just a natural part of our household diet, and, I guess because of having Asian influence there, so it just comes in with all the rest of it [other types of meat] as equal value"

(Group 2, male, mean child age 5 years)

For participants without a cultural background associated with high pork consumption (such as those with 
Table 2 Summary of key themes and sub-themes identified in the focus groups

\begin{tabular}{|c|c|}
\hline Key theme & Sub-theme \\
\hline Family pork practices & - Parents' preferences influencing children's pork intake \\
\hline \multirow[t]{2}{*}{ Pork as part of tradition and culture } & - Pork preferences influenced by cultural background \\
\hline & - Pork perceived as a meal for special occasions \\
\hline \multirow[t]{4}{*}{ Preparing and cooking pork } & - Parents' perceptions that pork is acceptable to prepare \\
\hline & - Perception that pork needs to be cooked until well done \\
\hline & - Lack of confidence or experience with cooking pork \\
\hline & - Need for pork recipes and cooking inspiration \\
\hline \multirow[t]{3}{*}{ Consumer awareness and visibility of pork } & - Lack of visibility of pork in retail outlets \\
\hline & - Lack of access to a variety of pork cuts \\
\hline & - Lack of visibility of pork in the media \\
\hline \multirow[t]{2}{*}{ Healthfulness of pork } & - Overall fresh pork perceived as healthy \\
\hline & - Concerns relating to high fat/sodium content of processed pork \\
\hline \multirow[t]{2}{*}{ Perceptions of processed pork } & - Processed pork as a convenience food \\
\hline & - Children's preferences for processed pork products \\
\hline \multirow[t]{5}{*}{ Children's pork preferences and barriers to intake } & - Children's preference for processed pork \\
\hline & - Children's preferences for pork as part of a mixed dish \\
\hline & - Children's involvement with cooking/preparing pork meals encouraging intake \\
\hline & - Fussy eating behaviour limiting pork intake \\
\hline & - Texture/perceived fattiness of pork as a barrier to fresh pork intake \\
\hline
\end{tabular}

an Australian or European background), there was a strong link between the intake of fresh pork and special occasions. In particular, roast pork was specifically discussed as being a key element at Christmas, and, for some participants, birthdays. This tradition tended to be based on the participant's own childhood experiences and now formed part of the family traditions that they had developed for their own children.

"..."The Christmas thing resonated with me as well, growing up in Australia...I still have to do a roast pork in a couple of weeks' time [for Christmas], cos my father refuses to let go of it. Um but also we used to get it as a special treat on our birthdays, you could have a roast pork, a leg of pork on your birthday...it was primarily um for special occasions and stuff"

(Group 1, female, mean child age 10.5 years)

Religion did not directly impact on fresh pork consumption for the majority of participants, although the concept of avoiding pork because of certain religious beliefs was discussed throughout the groups.

\section{Preparing and cooking pork}

Overall, fresh pork was perceived to be an acceptable meat to prepare for feeding children as well as other members of the family. In terms of the convenience of cooking and the time involved to prepare pork, it was seen as being similar to other meats such as beef, although chicken was perceived to be the most convenient and easiest meat to prepare.

Throughout the focus groups, there was a strong perception amongst participants that fresh pork needed to be cooked until it was well done, with a number of participants expressing concern about pink colour remaining in their pork when they had cooked it. A number of reasons for this concern were raised including a fear of food poisoning and a fear of contracting intestinal worms as a result of eating undercooked pork. Pork was perceived to be linked to a greater risk of food poisoning than meats such as beef or lamb, with the risk of food poisoning associated with undercooking pork perceived to be similar to the risk associated with consuming undercooked chicken. These perceptions remain despite recent guidance on cooking practices of pork suggesting that it is not necessary to cook pork until it is well done or cooked through. Instead, pork may be safely cooked in a similar manner to beef or lamb with some pink colour remaining [32]. Ensuring that this information is widely available for the general population may overcome some of the textural concerns associated with overcooking fresh pork, which emerged during the focus groups.

"I do I make sure I cook it [pork] well because I know it can't um be pink like your beef, it's got to be cooked like you cook your chicken" 
(Group 1, female, mean child age 12)

A lack of confidence or experience in cooking fresh pork was a commonly identified barrier against serving it for children. Many participants felt that fresh pork was not a meat they had had a lot of exposure to or had experience in preparing and as a result parents lacked confidence when cooking pork dishes for their families. As well as concern related to undercooking pork, participants throughout the groups also expressed caution regarding overcooking pork, in case it became too dry and was rejected by children.

Many participants expressed a strong desire for new recipes as inspiration for new ways to cook pork for their children. Compared to other meats, participants had fewer recipe ideas for fresh pork within their meal repertoire, which negatively impacted upon their desire to serve it to their families.

"I'd say if the...the, pork manufacturers want to encourage me to eat more pork, I probably need it to be presented in, these are all the different things you can do with pork, maybe ways that I haven't thought about pork"

(Group 6, female, mean child age 15 years)

\section{Consumer awareness and visibility of pork}

A large proportion of participants viewed pork as being less visible in shopping outlets than other meats such as beef and chicken. A common viewpoint was that the space allocated to fresh pork in supermarkets or delicatessens was much less than that allocated to other meats, which they felt discouraged them from purchasing it for their children. Participants also reported occasionally missing fresh pork in some outlets, due to it being positioned in a slightly different location to other meats, again resulting in an overall lack of visibility of pork.

"I think in supermarkets as well there's, you go in there's a massive say beef or chicken section, and pork is, sometimes you've got to hunt for it"

(Group 1, male, mean child age 6.5 years)

Compared to other meats such as beef, participants perceived the variety of pork cuts available in shopping outlets to be limited mostly to pork chops and pork roasts. This observation was discussed as having a detrimental impact on their perception of the versatility of pork and thus presented another barrier to purchasing pork for their families.

"But when you go shopping there's only just so many different ways you know that they sell it, like you get the medallions or you get the pork chops or you get the roast pork or you get the mince, there isn't really anything else"

(Group 1, female, mean child age 6.25 years)

Television cooking programs such as Masterchef have been reported to be influential in inspiring confidence in cooking [33] and may also influence food purchasing behaviour. Participants discussed that television cooking programs may influence their decision to purchase, as well as their children's willingness to eat foods appearing in these programs. Such programs were repeatedly referred to as a source of cooking information throughout the focus groups, and due to this inspiration and the increased familiarity with products featured on such programs reported in the groups, many participants felt they would purchase more fresh pork for their children if it was featured on a television program.

"If I saw it on one of the big shows, yeah I'd definitely go out and buy it then. And if it tasted good, which it usually does when you see it on TV it looks like it's going to taste nice, and then in your head it tastes nice, then it'd probably appear on the menu for a while"

(Group 2, male, mean child age 9 years)

\section{Perceived healthfulness of pork}

Overall, the general perception of participants was that fresh pork was a healthy meat, although the healthfulness of pork was perceived to be related to the specific cut selected and the cooking method used. Several participants discussed avoiding particular items such as pork belly and pork ribs due to their perceived higher fat content. However, there was also a consistent perception amongst participants that pork has become leaner than in previous years, which is consistent with changes in breeding practices of the Australian Pork Industry [34]. In contrast, several participants discussed their concerns relating to the high sodium and/or fat content of processed pork products including ham, bacon and cured pork products.

A key theme identified in relation to the healthfulness of pork was that consumers were unaware of the nutritional profile of fresh pork as compared to other meats. A need for more information on the unique nutritional benefits of pork was clearly articulated within the groups.

"I think the other thing that might help in terms of purchasing pork and that sort of thing is, is maybe knowing more of the health benefits...I think um, when 
I think of why do we include meat in our meals, is for the protein and that sort of thing and I will tend to go out of my way to buy beef and lamb, because I know that they're good sources of iron, whereas, I actually don't know [laughs] um, like why I, I'd specially go for pork"

(Group 4, female, mean child age 5 years)

\section{Processed pork as a convenience food}

Processed pork was discussed by many group participants as an easy and convenient food that was well accepted by their children. Processed pork items such as bacon and ham in particular were discussed as versatile additions to meals which were easy to prepare when time was poor.

"Ours is definitely convenience, we've always got bacon in the fridge, bacon sandwiches, pasta, you can just, you can do so much with it"

(Group 1, male, mean child age 6.5 years)

A greater confidence in their ability to prepare meals containing processed pork compared to fresh pork was also discussed by several group members. Processed pork was discussed as being easy to cook (if required) and as such more readily prepared by parents or carers.

"I think there's probably more confidence associated with those foods, so ham you don't even have to cook, you might put it on a sandwich, and like bacon, I'm pretty confident in cooking my bacon, ahh so compared to, say a pork steak, so I guess it's you know the versatility"

(Group 6, female, mean child age 7 years)

\section{Children's pork preferences and barriers to intake}

Parents reported that their children enjoyed both fresh and processed pork, although a greater preference for processed variants was expressed, which is in line with patterns of consumption that have been identified previously [6]. This may be due to the familiarity of processed pork if it is offered more frequently by parents for the reasons of convenience and versatility previously identified. Birch and Marlin [35] identified that children's preferences for particular foods are proportional to the number of exposures to that particular food, which may play a role in the stronger preferences for processed pork identified in the study.

When considering fresh pork, many participants reported that their children preferred dishes where pork was presented as part of a mixed dish such as a curry or stir fry rather than as a single piece of meat. The exception to this was for roast pork, with several parents reporting that their children enjoyed pork prepared in this way with crackling (particularly if served with a sauce or marinade).

Involving children in the preparation of dishes containing fresh pork such as pork dumplings or meat balls was identified as a strategy used by parents/careers to improve the acceptance of these meals, as was preparing meals which required children to use their hands. Increasing the engagement of children in the preparation of meals has been found to increase their acceptance of a variety of healthy food options [36].

"Yeah I must say fun foods seem to work with our guys at the moment, I often do pork mince in tacos in things like that and because the kids are allowed to eat with their hands they absolutely love it, makes a big mess..."

(Group 3, female, mean child age 3 years)

Barriers to children consuming fresh pork were also discussed. Fussy eating behaviour was identified as a barrier to feeding a variety of foods including pork to children. Parents agreed that they preferred to serve foods that they knew their children would eat such as chicken dishes, to avoid arguments.

\section{"And so I'm just like, well I'm just gonna give her chicken, mashed potato, peas and corn and carrots and I know she is gonna sit and eat all that and then it's my peace and quiet and I know, you know I should get her to try different things, but sometimes it's just simpler not to"}

(Group 6, female, mean child age 7 years)

Several participants discussed their children's perceptions of fresh pork as a fatty meat, which acted as a barrier to their willingness to eat it. This tended to be discussed more in parents of older children aged 12 years and above and was often associated with an increased interest in health and nutrition in this age group. A small number of participants with younger children discussed their children's aversion to a fatty flavour, which they perceived to be associated with pork. The perception of pork as a fatty meat has previously been reported, with adult consumers perceiving pork to be less lean than beef or chicken [37], although contradictory results have also been reported in the literature [16]. Australian food composition data suggests that the fat content of pork is comparable to that of beef and chicken [38-40]. When considered in light of the lack of awareness of the nutrition profile of pork reported in the current study, these findings suggest confusion regarding pork's nutrient composition. 
"I think my kids... they see pork as a, a fatty meat, and that's one thing they don't like about eating meat"

(Group 2, male, mean child age 14 years)

The texture of fresh pork was viewed as being a potential barrier to consumption in younger children, although this issue tended to be reduced in older children. Texture was primarily considered to be an issue in the event that the pork had been overcooked and become dry, with pork chops and steaks viewed as being the cuts most likely to be rejected due to texture.

"We've got a three year old and chicken is much easier for them to eat and chew on than red meat and pork if it's, if it's a chop or something, they don't seem to like it that much"

(Group 2, male, mean child age 5 years)

This research was an exploratory study, and due to its small sample size, caution should be used if results are sought to be extrapolated to the broader Australian population. In particular, whilst the proportion of participants with a university education did not differ between recruitment locations, the proportion of participants with post-school qualifications was higher than that reported for the region as a whole [41]. This discrepancy in education levels may have influenced participant's perceptions and suggests that the results of this study should not be generalised to the wider population.

\section{Conclusions}

This research was an exploratory study which has however provided some important insights into factors that influence children's pork consumption. Understanding these factors is particularly important given the unique positioning of pork in the diet, as indicated by the apparent preference for processed varieties not observed with other meat types. The findings of this study may be informative when seeking to provide targeted dietary strategies to reduce intakes of processed meat, as well as encouraging diversity in choices of lean fresh meat by children.

Overall, fresh pork was considered to be a healthy meat option, but a need for convenient recipes that would appeal to children was identified. A need for more information regarding both the unique nutrition characteristics of fresh pork and suitable cooking methods was also identified. The observed preference for processed pork over fresh pork by many Australian children may relate to the increased familiarity and confidence of parents with serving this type of meat to their children.
This study is the first to explore barriers to children's pork intake. Given the known influence of childhood eating habits on those sustained through the lifespan, investigation into factors influencing food intake in childhood is warranted. The results of this study suggest that dietetic strategies to help address the aforementioned barriers to intake, including recipe development and dissemination of information on pork nutrient profile and cooking methods, may help to position fresh pork more prominently in the meal repertoire of Australian families and future generations.

\section{Competing interests}

This study was funded by an innovation grant from the Pork Co-operative Research Centre. The publication charges of the manuscript were included under this grant amount. The funding body was not involved in the collection, analysis, interpretation or presentation of data. Karen Charlton receives an honorarium from the Pork Co-operative Research Centre for her work as a sub-program manager (3B: Inherent Properties of Australian Pork to Enhance Consumer Health). The other authors declare no conflicts of interest.

\section{Authors' contributions}

EN was involved in the design of the study, observation of the focus groups, analysis of the data and development of the manuscript. DNC was involved in the design of the study, moderation of the focus groups, analysis of the data and development of the manuscript. KC was involved in the design of the study, observation of the focus groups, analysis of the data and development of the manuscript. All authors read and approved the final manuscript.

\section{Author details}

${ }^{1}$ Landmark Nutrition Pty Ltd, New South Wales, Australia. ${ }^{2}$ School of Medicine, Faculty of Science, Medicine and Health, University of Wollongong, New South Wales, Australia.

Received: 15 February 2015 Accepted: 16 April 2015

Published online: 30 July 2015

\section{References}

1. Department of Health and Ageing, National Health and Medical Research Council. Australian dietary guidelines. 2013.

2. World Cancer Research Fund. Food, nutrition, physical activity and the prevention of cancer: a global perspective. 2007.

3. National Health and Medical Research Council. Nutrient reference values for Australia and New Zealand including recommended dietary intakes. 2006.

4. NUTTAB 2010 [database on the Internet] 2011. Available from: http:// www.foodstandards.gov.au/consumerinformation/nuttab2010/. Accessed:

5. Department of Health and Ageing, Australian Food and Grocery Council, Department of Agriculture Fisheries and Forestry. 2007 Australian National Children's Nutrition and Physical Activity Survey - Main Findings. Canberra 2009.

6. Nolan-Clark DJ, Neale EP, Charlton KE. Processed pork is the most frequently consumed type of pork in a survey of Australian children. Nutr Res. 2013;33(11):913-21. doi:10.1016/j.nutres.2013.08.003.

7. Bowen J, Baird D, Syrette J, Noakes M, Baghurst K. Consumption of beef/ veal/lamb in Australian children: intake, nutrient contribution and comparison with other meat, poultry and fish categories. Nutr Dietetics. 2012;69:1-16. doi:10.1111/j.1747-0080.2012.01642.x.

8. Australian Bureau of Statistics. 4364.0.55.007-Australian Health Survey: nutrition first results - foods and nutrients, 2011-12. Canberra 2014.

9. Kelder SH, Perry CL, Klepp Kl, Lytle LL. Longitudinal tracking of adolescent smoking, physical activity, and food choice behaviors. Am J Public Health. 1994;84(7):1121-6. doi:10.2105/ajph.84.7.1121.

10. Puhl RM, Schwartz MB. If you are good you can have a cookie: how memories of childhood food rules link to adult eating behaviors. Eating Behaviors. 2003;4(3):283-93. http://dx.doi.org/10.1016/S1471-0153(03)00024-2.

11. Mikkila V, Rasanen L, Raitakari OT, Pietinen P, Viikari J. Longitudinal changes in diet from childhood into adulthood with respect to risk of 
cardiovascular diseases: the cardiovascular risk in young Finns study. Eur J Clin Nutr. 2004;58(7):1038-45.

12. Savage JS, Fisher JO, Birch LL. Parental influence on eating behavior: conception to adolescence. J Law Med Ethics. 2007;35(1):22-34. doi:10.1111/j.1748-720X.2007.00111.x.

13. Kitzinger J. The methodology of focus groups: the importance of interaction between research participants. Sociol Health IIIn. 1994:16(1):103-21. doi:10.1111/1467-9566.ep11347023.

14. Kitzinger J. Qualitative research: introducing focus groups. BMJ. 1995;311(7000):299-302. doi:10.1136/bmj.311.7000.299.

15. Bryhni EA, Byrne DV, Rodbotten M, Claudi-Magnussen C, Agerhem H, Johansson $\mathrm{M}$, et al. Consumer perceptions of pork in Denmark, Norway and Sweden. Food Qual Pref. 2002;13(5):257-66. doi:10.1016/s09503293(02)00021-6.

16. Ngapo TM, Dransfield E, Martin JF, Magnusson M, Bredahl L, Nute GR. Consumer perceptions: pork and pig production. Insights from France, England, Sweden and Denmark. Meat Sci. 2003;66(1):125-34. doi:10.1016/s0309-1740(03)00076-7.

17. McCarthy M, O'Reilly S, Cotter L, de Boer M. Factors influencing consumption of pork and poultry in the Irish market. Appetite. 2004:43(1):19-28. doi:10.1016/..appet.2004.01.006.

18. Bredahl L, Poulsen C. Perceptions of pork and modern pig breeding among Danish consumers. The Aarhus School of Business. 2002; Project paper no. 01/02.

19. Verbeke W, Viaene J. Beliefs, attitude and behaviour towards fresh meat consumption in Belgium: empirical evidence from a consumer survey. Food Qual Pref. 1999;10(6):437-45. doi:10.1016/s0950-3293(99)00031-2.

20. Wong LP. Focus group discussion: a tool for health and medical research. Singapore Med J. 2008;49(3):256-60.

21. Krueger R, Casey M. Focus groups: a practical guide for applied research. 5th ed. California: Sage Publications Inc.; 2015.

22. Ritchie J, Lewis J, O'Connor G. Analysis: practices, principles and processes. In: Ritchie J, Lewis J, editors. Qualitative research practice: a guide for social science students and researchers. London: Sage; 2003.

23. Ritchie J, Spencer L. Qualitative data analysis for applied policy research. In: Byman A, Burgess $R$, editors. Analyzing qualitative data London: Routledge. 1994. p. 173-95.

24. Burt J, Shipman C, Addington-Hall J, White P. Nursing the dying within a generalist caseload: a focus group study of district nurses. Int J Nurs Stud. 2008;45(10):1470-8. doi:10.1016/j.ijnurstu.2008.01.003.

25. Jefferies $\mathrm{H}$, Clifford $\mathrm{C}$. Aloneness: the lived experience of women with cancer of the vulva. Eur J Cancer Care. 2011;20(6):738-46. doi:10.1111/ j.1365-2354.2011.01246.x.

26. Miller N, Taylor J, Howe C, Read J. Living with foreign accent syndrome: insider perspectives. Aphasiology. 2011;25(9):1053-68. doi:10.1080/02687038.2011.573857.

27. Murtagh J, Dixey R, Rudolf M. A qualitative investigation into the levers and barriers to weight loss in children: opinions of obese children. Arch Dis Child. 2006;91(11):920-3. doi:10.1136/adc.2005.085712.

28. Walker O, Strong M, Atchinson R, Saunders J, Abbott J. A qualitative study of primary care clinicians' views of treating childhood obesity. BMC Family Practice. 2007;8. doi:5010.1186/1471-2296-8-50.

29. Webber L, Cooke L, Wardle J. Maternal perception of the causes and consequences of sibling differences in eating behaviour. Eur J Clin Nutr. 2010;64(11):1316-22. doi:10.1038/ejcn.2010.159.

30. Wood F, Robling M, Prout H, Kinnersley P, Houston H, Butler C. A question of balance: a qualitative study of mothers' interpretations of dietary recommendations. Ann Fam Med. 2010:8(1):51-7. doi:10.1370/afm.1072.

31. Birch LL, Fisher JO. Development of eating behaviors among children and adolescents. Pediatrics. 1998;101(3):539-49.

32. Australian Pork Limited. 2014. http://www.pork.com.au.

33. Australian Institute of Health and Welfare. Australia's food and nutrition 2012. Canberra 2012: AlHW.

34. Dunshea FR, D'Souza DN, Pethick DW, Harper GS, Warner RD. Effects of dietary factors and other metabolic modifiers on quality and nutritional value of meat. Meat Science. 2005;71(1):8-38. http://dx.doi.org/10.1016/ j.meatsci.2005.05.001.

35. Birch LL, Marlin DW. I don't like it, I never tried it: effects of exposure on two-year-old children's food preferences. Appetite. 1982;3(4):353-60.

36. Larson NI, Story M, Eisenberg ME, Neumark-Sztainer D. Food preparation and purchasing roles among adolescents: associations with sociodemographic characteristics and diet quality. J Am Diet Assoc. 2006;106(2):211-8. doi:10.1016/j.jada.2005.010.029.

37. Verbeke W, Van Oeckel MJ, Warnants N, Viaene J, Boucqué CV. Consumer perception, facts and possibilities to improve acceptability of health and sensory characteristics of pork. Meat Science. 1999;53(2):77-99. http://dx.doi.org/10.1016/S0309-1740(99)00036-4.

38. Greenfield H, Arcot J, Barnes JA, Cunningham J, Adorno P, Stobaus T, et al. Nutrient composition of Australian retail pork cuts 2005/2006. Food Chem. 2009;117(4):721-30. doi:10.1016/j.foodchem.2009.04.048.

39. Probst Y. Nutrient Composition of Chicken Meat 2009 Contract No.: RIRDC Publication No 08/210.

40. Williams P, Droulez V, Levy G, Stobaus T. Composition of Australian red meat 2002-3. Nutrient profile. Food Australia. 2007;59(7):331-41.

41. Australian Bureau of Statistics. 1379.0.55.001 - National Regional Profile, 2008 to 2012. Canberra 2014

\section{Submit your next manuscript to BioMed Central and take full advantage of:}

- Convenient online submission

- Thorough peer review

- No space constraints or color figure charges

- Immediate publication on acceptance

- Inclusion in PubMed, CAS, Scopus and Google Scholar

- Research which is freely available for redistribution 